\title{
Yetişkin Bireylerde Vücut Farkındalığı ve Antropometrik Ölçümlerle İlişkisi
}

\author{
Relationship Between Body Awareness and Anthropometric Measurements in Adults
}

\author{
Emine Koçyiğit ${ }^{1}$, Neslihan Arslan², Eda Köksal ${ }^{3}$
}

Geliş tarihi/Received: 22.06.2018 • Kabul tarihi/Accepted: 18.11.2018

\section{ÖZET}

Amaç: Bu çalışma yetişkin bireylerde vücut farkındalığının ve bunun antropometrik ölçümlerle ilişkisinin saptanması amacıyla planlanmış ve yürütülmüştür.

Bireyler ve Yöntem: Çalışma, araştırma kriterlerine uygun olan ve katılmayı kabul eden 80 sağlık çalışanı üzerinde yapılmıştır. Araştırmacılar tarafından yüz yüze görüşme yöntemi ile uygulanan anket formu kapsamında bireylerin genel bilgileri, sağlık bilgileri, antropometrik ölçümleri ve vücut bileşimleri alınmış, vücut figürü skalası ve vücut farkındalık anketi uygulanmıştır.

Bulgular: Araştırmaya katılan erkeklerin yaş ortalaması $27.4 \pm 2.70$ yll, kadınların $27.0 \pm 2.05$ ylldır. Erkeklerin \%45.9’u, kadınların \%76.7’si normal ağırlıktadır. Her iki cinsiyetin de vücut figürü skalasına göre beden algısı değerlendirmesini doğru yaptığı saptanmıştır. Vücut figürünü doğru değerlendiren erkeklerin vücut farkındalık skoru, yanlış değerlendirenlerden anlamlı oranda daha yüksektir. Bireylerin vücut farkındalık skoru ortalamaları ile yaş, antropometrik ölçümler ve vücut bileşimleri arasında anlamlı bir ilişki saptanmamıştır ( $\mathrm{p}>0.05)$.

Sonuç: Araştırmaya katılan bireylerin yarısından fazlasının vücut ağırlığını doğru tahmin ettiği, vücut figürü değerlendirmesini doğru yapan erkeklerin vücut farkındalık skorlarının daha yüksek olduğu görülmüştür. Bireylerin tamamının üniversite mezunu olup sağlık alanında eğitim almış olmaları ile bu alanda çalışmaya devam etmelerinin beden ağırlığının doğru değerlendirilmesine katkı sağlayan en önemli etmen olduğu düşünülmektedir. Araştırma sonuçlarının genele yayılabilmesi ve kanıt değerinin arttırabilmesi için daha fazla örneklem sayısına sahip, bireylerin sosyal ve mesleki yaşantısı, çalışma koşulları, aktivite düzeyi ve emosyonel durumu gibi birçok etmenin bir arada değerlendirildiği çalışmalara gerek duyulmaktadır.

Anahtar kelimeler: Vücut figürü skalası, vücut farkındalı̆̆l, beslenme

\section{ABSTRACT}

Aim: This study is conducted to evaluate the relationship between body awareness and anthropometric measurements.

Subjects and Method: The study was carried out on 80 health professionals working in the Faculty of Health Sciences of Gazi University, who complied with the research criteria and agreed to participate. The study questionnaire prepared by the researchers was applied to participants through face to face method included general and health information. Anthropometric measurements and body composition analysis were performed. Body figure scale and body awareness questionnaires were also applied.

1. İletişim/Correspondence: Gazi Üniversitesi Sağlık Bilimleri Fakültesi Beslenme ve Diyetetik Bölümü, Ankara, Türkiye

E-posta: evrims1979@yahoo.com• • ㄴ https://orcid.org/0000-0002-9459-9557
2. Gazi Üniversitesi Sağlık Bilimleri Fakültesi Beslenme ve Diyetetik Bölümü, Ankara, Türkiye • (1) https://orcid.org/0000-0002-1232-8009

3. Gazi Üniversitesi Sağllk Bilimleri Fakültesi Beslenme ve Diyetetik Bölümü, Ankara, Türkiye • 으 https://orcid.org/0000-0002-7930-9910 
Results: The mean age of the males and females was $27.4 \pm 2.70$ years and $27.0 \pm 2.05$ years respectively. According to the body figure scale, the participants of both gender estimated their body image correctly. The mean body awareness scale was significantly higher in male participants who estimated their body figure correctly compared to who estimated their body figure incorrectly. There were no significant correlations of the mean body awareness scores with age, anthropometric measurements and body composition ( $\mathrm{p}>0.05)$.

Conclusion: In this study, more than half of the participants predicted their body figures correctly and the mean body awareness scores were found to be higher in male participants who accurately evaluated their body figures. The fact that all of the individuals were university graduates who had been educated in the field of health, and who continue to work in this field. These were the most important factors contributing to the accurate evaluation of body figure. It is necessary to evaluate other factors such as social and occupational experiences, working conditions, activity level and emotional status of individuals with larger sample sizes in order to interpret the results for a wider population.

Keywords: Figure rating scale, body awareness, nutrition

\section{GíRiş}

Vücut farkındalığı duyusal farkındalık ile organizmanın tüm duygusal ve fizyolojik durumunu içeren çok yönlü bir kavramdır (1,2). Vücut farkındalığı aynı zamanda, günlük hayatta bedensel bilgiyi kullanmayı, vücutta oluşan değişiklikleri fark etmeyi ve çevrede gelişen değişikliklere karşı duygusal olarak tepki göstermeyi içermektedir. Temel düzeyde bireyin vücut şekli konusunda ne kadar bilgi sahibi olduğunu tanımlamaktadır. Son yıllarda, vücut farkındalığı özellikle sağlık alanında yapılan bilimsel araştırmalarda öne çıkmaktadır (1-3).

Vücut farkındalığı kavramı geleneksel anlamda anksiyete ve panik bozuklukların tanımlanmasinda kullanılmış, yaşam kalitesi, duygusal durum ve ağrı üzerine etkisi çalışmalarla değerlendirilmiş, daha sonra pilates, klinik pilates, yoga gibi farkındalığın önem teşkil ettiği sağlık bilimleri alanında tedavi yöntemi olarak kullanılmaya başlanmıştır $(3,4)$.

Beden imajı, vücut farkındalığı ile ilgili diğer bir unsur olarak karşımıza çıkmaktadır $(5,6)$. Bireyin vücudunu nasıl gördüğü ve değerlendirdiği ile ilgili bilgi edinmemizi sağlamaktadır. Böylece bireyin algısını somut bir şekilde ortaya koymaktadır. Bu yönüyle vücut farkındalığı yeme bozuklukları başta olmak üzere birçok nörolojik ve psikiyatrik hastalığın araştırılmasında kullanılmıştır (5-7). Belirtilen sağlık sorunlarının yanında vücut farkındalığı obezite, yeme davranışı, ağırlık kaybı, besin tercihi gibi pek çok konuda bireyi etkilemektedir (8-10). Yıllar geçtikçe bireylerin özellikle ağırlık algısında değişim gözlenmekte, genellikle zayıf insanların kendilerini olduklarından daha şişman olarak tanımladığı, şişman insanların da ağırlıklarının farkında olmayarak kendilerini daha zayıf olarak tanımladıkları belirtilmektedir $(11,12)$.

Vücut farkındalığı pek çok hastalıkla ilişkilendirilmesine rağmen, literatürde vücut farkındalığı ve antropometrik ölçümleri bir arada değerlendiren çalışmaların sayısı sınırlıdır. $\mathrm{Bu}$ çalışma yetişkin bireylerde vücut farkındalığını ve bunun antropometrik ölçümlerle ilişkisini araştırmak amacıyla planlanıp yürütülmüştür.

\section{BİREYLER VE YÖNTEM}

\section{Araştırmanın Yeri, Zamanı ve Örneklem Seçimi}

$\mathrm{Bu}$ araştırma Gazi Üniversitesi Sağlık Bilimleri Fakültesi’nde sağlık çalışanı olarak görev yapan 37 erkek, 43 kadın toplam 80 gönüllü birey ile yürütülmüştür. Yapılan güç analizi sonucu beta $\% 90$ güç, \%5 hata payı ile 80 örnek sayısı yeterli bulunmuştur. Gebe ve emzikliler çalışmaya dahil 
edilmemiştir. Eksik bilgi beyan eden 2 kişi çalışma dışı bırakılmıştır.

Araştırma için Gazi Üniversitesi Etik Komisyon'undan 19.12.2017 tarih ve 77082166.302.08.01 karar numaralı "Etik Komisyon Onayı" alınmıştır. Bireyler çalışmanın içeriği ve süresi konusunda sözlü olarak bilgilendirilmiş ve araştırmayı kabul edenlere gönüllü onam formu imzalatılmıştır.

\section{Araştırmanın Genel Planı}

Araştırma kriterlerine uygun olan ve araştırmaya katılmayı kabul eden bireylere araştırmacı tarafından yüz yüze görüşme yöntemi ile anket formu uygulanmıştır. Anket formu bireylerin genel bilgileri ve sağlık bilgileri soruları, antropometrik ve vücut bileşimleri ölçümleri ile vücut figürü skalası ve vücut farkındalık anketinden oluşmaktadır.

\section{Verilerin Toplanması}

Antropometrik ölçümler: Vücut ağırlığı (kg), vücut yağ oranı (\%), yağsız vücut kütlesi (kg) ve vücut su oranı (\%), ölçümleri Tanita BC 420MA marka (biyoelektrik impedans cihazı [BİA]) kullanılarak yapılmıştır. Ağırlık ölçümleri kg olarak ve $0.1 \mathrm{~kg}$ duyarlılıkla kaydedilmiştir. Bel, boyun çevresi ve boy uzunluğu ölçümleri tekniğine uygun olarak araştırmacılar tarafından alınmıştır. Bel ve boyun çevresi ölçümleri için esnemeyen plastik mezür, boy uzunluğu için taşınabilir Leicester marka stadiometre (boy ölçer) kullanılmıştır. Ölçümler cm olarak ve $0.1 \mathrm{~cm}$ duyarlılıkla kaydedilmiştir (13). Beden kütle indeksi (BKİ), vücut ağırlığı ve boy uzunluğu ölçümleri kullanılarak "vücut ağırlığı/boy uzunluğu $\left(\mathrm{kg} / \mathrm{m}^{2}\right)$ denklemi ile hesaplanmıştır. Elde edilen BKI değerleri Dünya Sağlık Örgütü (WHO) sinıflamasına göre değerlendirilmiştir (14).

Bel çevresi erkeklerde <94 cm normal, 94-102 cm aralığı riskli, $>102 \mathrm{~cm}$ yüksek risk, kadınlarda $<80$ cm normal, $80-88 \mathrm{~cm}$ aralığı riskli, $>88 \mathrm{~cm}$ yüksek risk olarak sınıflandırılmıştır (15). Boyun çevresinin erkeklerde $>37 \mathrm{~cm}$, kadınlarda $>34 \mathrm{~cm}$ üzerindeki değerleri yüksek vücut ağırlığı ve obezite için risk etmenidir (16). Vücut yağ yüzdesi erkeklerde $\leq \% 8$ zayıf, \%8.1-19.9 normal, \%20-24.9 hafif şişman, $\geq \% 25$ obez, kadınlarda $\leq \% 21$ zayıf, \%21.1-32.9 normal, \%3338.9 hafif şişman, $\geq \% 39$ obez olarak değerlendirilmiştir (17).

Vücut figürü skalası: Bireylerin vücut ağırlıklarını tanımlaması için Stunkard tarafından geliştirilen vücut figürü skalası kullanılmıştır (18). Skala erkek ve kadın bireyler için ayrı ayrı 9 vücut figüründen oluşmaktadır. Skalaya göre 1 ve 2'yi işaretleyenler zayıf, 3 ve 4'ü işaretleyenler normal ağırlıkta, 5, 6 ve 7’yi işaretleyenler hafif şişman, 8 ve 9'u işaretleyenler obez olarak değerlendirilmektedir.

Vücut farkındalık anketi: Özgün adı Body Awareness Questionaire (BAQ) olan vücut farkındalığı anketi, Shields ve arkadaşları (19) tarafindan 1989 yılında geliştirilmiştir. Likert tipi anket 18 madde ve 4 alt gruptan oluşmakta anketten alınan yüksek puan vücut farkındalığının yüksek olduğunu göstermektedir. Anket Karaca ve arkadaşları (20) tarafindan 2017 yılında Türkçe’ye uyarlanmıştır.

\section{Verilerin İstatistiksel Değerlendirmesi}

İstatistiksel analizler SPSS (IBM SPSS Statistics 20.0) paket programı kullanılarak yapılmıştır. Bulguların yorumlanmasında frekans tabloları ve tanımlayıcı istatistikler kullanılmıştır. Kolmogrov Smirnov normalite testi uygulanarak normal dağılıma uygun ölçüm değerleri için parametrik yöntemler kullanılmıştır. Parametrik yöntemlere uygun şekilde, iki bağımsız grubun ölçüm değerleri ile karşılaştırılmasında Indepedent Sample-t test (t-tablo değeri) yöntemi kullanılmıştır. Normal dağılıma uygun olmayan ölçüm değerleri için parametrik olmayan yöntemler kullanılmıştır. Parametrik olmayan yöntemlere uygun şekilde, iki bağımsız grubun ölçüm değerleri ile karşılaştırılmasında Mann-Whitney U test (Z-tablo değeri) yöntemi kullanılmıştır.

Normal dağılıma sahip olan iki ölçüm değerinin birbiriyle ilişkilerinin incelenmesinde Pearson, en az bir ölçüm değerinin normal dağılıma sahip olmaması durumunda Spearman korelasyon katsayısı 
kullanılmıştır. BKİ sınıflaması ile vücut figürü skalası uyumu kappa ( $\kappa$ ) istatistiği ile değerlendirilmiştir. Elde edilen $\kappa$ değerleri 0.01-0.20 önemsiz düzeyde, 0.21-0.40 zaylf düzeyde, $0.41-0.60$ orta düzeyde, 0.61 0.80 iyi düzeyde ve $0.81-1.00$ çok iyi düzeyde uyuma göre sınıflandırılarak yorumlanmıştır (21). Sonuçlar \%95 güven aralığında, istatistiksel olarak $\mathrm{p}<0.05$ önemlilik düzeyinde değerlendirilmiştir.

\section{BULGULAR}

Araştırma yaş ortalaması 27.4 \pm 2.70 yıl olan 37 erkek ve yaş ortalaması $27.0 \pm 2.05$ yıl olan 43 kadın bireyle yürütülmüştür ( $p>0.05)$. Bireylerin genel özellikleri ve sağlık bilgileri Tablo 1'de gösterilmiştir. Erkeklerin \%67.6’sı, kadınların \%67.4'ü evlidir. Erkeklerin kronik bir hastalığı bulunmazken, kadınların \%14.0'ünün kronikhastalığı (migren, alerjik astım, haşimato tiroidi, venöz yetmezlik, polikistik over sendromu, bel fitığı) vardır (Bu veri tabloda gösterilmemiştir). Erkeklerin \%43.2'si, kadınların \%4.7'si sigara kullanırken, alkol tüketimi erkeklerde \%16.2, kadınlarda \%14.0 olarak bulunmuştur. Değişkenler açısından cinsiyete göre anlamlı fark bulunmamıştır ( $\mathrm{p}>0.05)$.

Tablo 1. Bireylerin genel özellikleri ve sağlık bilgileri

\begin{tabular}{lccc}
\hline Değişkenler & Erkek (n=37) & Kadın (n=43) & Toplam (n=80) \\
\cline { 2 - 4 } Medeni durum & $\mathbf{n}(\mathbf{\%})$ & $\mathbf{n}(\mathbf{\%})$ & $\mathbf{n}(\mathbf{\%})$ \\
$\quad$ Evli & $12(32.4)$ & $14(32.6)$ & $26(32.5)$ \\
$\quad$ Bekar & $25(67.6)$ & $29(67.4)$ & $54(67.5)$ \\
Kronik hastalık varlı̆̆ı & & & \\
$\quad$ Evet & - & $6(14.0)$ & $6(7.5)$ \\
$\quad$ Hayır & $37(100.0)$ & $37(86.0)$ & $74(92.5)$ \\
Sigara kullanımı & & & $18(22.5)$ \\
$\quad$ Evet & $16(43.2)$ & $2(4.7)$ & $62(77.5)$ \\
$\quad$ Hayır & $21(56.8)$ & $41(95.3)$ & $12(15.0)$ \\
Alkol tüketimi & & & $67(85.0)$ \\
$\quad$ Evet & $6(16.2)$ & $6(14.0)$ & $37(86.0)$ \\
$\quad$ Hayır & $31(83.8)$ & & \\
\hline
\end{tabular}

Bireylerin BKİ değeri, bel ve boyun çevresi ölçümleri ile vücut yağ yüzdelerinin referans değerlerine göre sınıflandırılması Tablo 2'de belirtilmiştir. Erkeklerin BKİ değeri ortalama $25.5 \pm 3.19 \mathrm{~kg} / \mathrm{m}^{2}$, kadınların ise $23.0 \pm 3.48 \mathrm{~kg} / \mathrm{m}^{2}$ olarak bulunmuştur (Veriler tabloda gösterilmemiştir). Araştırmaya katılan erkeklerin \%45.9’u hafif şişman, \%8.2'si obez, kadınların \%16.3’ü hafif şişman, \%4.7'si obezdir ( $p=0.018)$. Bel çevresi ölçümlerine göre erkeklerin \%13.5’i yüksek risk, kadınların \%9.3'ü yüksek riskli sınıfta yer almaktadır ( $p>0.05)$. Boyun çevresi ölçüm sinıflamasına göre erkeklerin \%70.3’ü, kadınların \%18.6'sı riskli grupta yer almaktadır ( $\mathrm{p}=0.001$ ). Vücut yağ yüzdesi değerlendirmesine göre ise istatistiksel olarak cinsiyetler arası fark yoktur ve erkeklerin \%29.7'si hafif şişman, \%16.2'si obez, kadınların \%7.0'si hafif şişman, \%11.6’sı obezdir ( $\mathrm{p}=0.008)$.

Vücut figürü skalasına göre bireylerin beden ağırlığı algısı Tablo 3’te verilmiştir. BKİ sınıflamasına göre normal ağırlıktaki erkeklerin \%70.6'sı kendini normal değerlendirirken, normal ağırlıktaki kadınlarda bu sıklık \%57.6 olarak bulunmuştur. Normal ağrılıktaki kadınların \%39.4'ü kendini zayıf görürken, \%3’ü obez olduğunu düşünmektedir. Obez erkeklerin tamamı kendini hafif şişman olarak değerlendirmekte, obez kadınlar ise normal ve hafif şişman olarak değerlendirmektedir. Erkeklerin BKİ ile beden ağırlığı algı sınıflaması arasındaki tutarlılığın düzeyi iyi iken $(\kappa=0.61, p=0.024)$, kadınların orta düzeydedir $(\kappa=0.53$, $\mathrm{p}=0.014)$. Toplamda erkeklerin \%59.4'ü (22/37), kadınların ise \%53.5’i (23/43) BKİ'sini vücut skalasına göre doğru değerlendirmiştir. 
Tablo 2. Bireylerin BKİ değeri, bel ve boyun çevresi ölçümleri ile vücut yağ yüzdelerinin referans değerlerine göre sinıflandirılması

\begin{tabular}{|c|c|c|c|}
\hline \multirow{2}{*}{ Değişkenler } & Erkek $(n=37)$ & Kadın $(n=43)$ & \\
\hline & n (\%) & n (\%) & \\
\hline \multicolumn{4}{|l|}{ BKİ $\left(\mathrm{kg} / \mathrm{m}^{2}\right)$} \\
\hline Zaylf $(<18.5)$ & - & $1(2.3)$ & \multirow{4}{*}{$x^{2}=10.093, p=0.018^{*}$} \\
\hline Normal ağırlık (18.5-24.99) & $17(45.9)$ & $33(76.7)$ & \\
\hline Hafif şişman (25.0-29.99) & $17(45.9)$ & $7(16.3)$ & \\
\hline Obez $(\geq 30)$ & $3(8.2)$ & $2(4.7)$ & \\
\hline \multicolumn{4}{|l|}{ Bel çevresi (cm) } \\
\hline Normal $(E<94, K<80)$ & $25(67.6)$ & $32(74.4)$ & \multirow{3}{*}{$x^{2}=0.524, p=0.770$} \\
\hline Risk $(E=94-102, \mathrm{~K}=80-88)$ & $7(18.9)$ & $7(16.3)$ & \\
\hline Yüksek risk (E>102, K>88) & $5(13.5)$ & $4(9.3)$ & \\
\hline \multicolumn{4}{|l|}{ Boyun çevresi (cm) } \\
\hline Normal $(E \leq 37, K \leq 34)$ & $11(29.7)$ & $35(81.4)$ & \multirow{2}{*}{$x^{2}=21.723, p=0.001 *$} \\
\hline Risk $(E>37, K>34)$ & $26(70.3)$ & $8(18.6)$ & \\
\hline \multicolumn{4}{|l|}{ Vücut yağ yüzdesi (\%) } \\
\hline Zaylf $(\mathrm{E} \leq 8, \mathrm{~K} \leq 21)$ & - & $6(14.0)$ & \multirow{4}{*}{$x^{2}=11.933, p=0.008^{*}$} \\
\hline Normal $(E=8.1-19.9, \mathrm{~K}=21.1-32.9)$ & $20(54.1)$ & $29(67.4)$ & \\
\hline Hafif şişman ( $\mathrm{E}=20-24.9, \mathrm{~K}=33-38.9)$ & $11(29.7)$ & $3(7.0)$ & \\
\hline Obez $(E \geq 25, K \geq 39)$ & $6(16.2)$ & $5(11.6)$ & \\
\hline
\end{tabular}

${ }^{*} p<0.05$, BKI: Beden kütle indeksi

Tablo 3. Bireylerin vücut figürü skalasına göre beden ağırlığı algısı

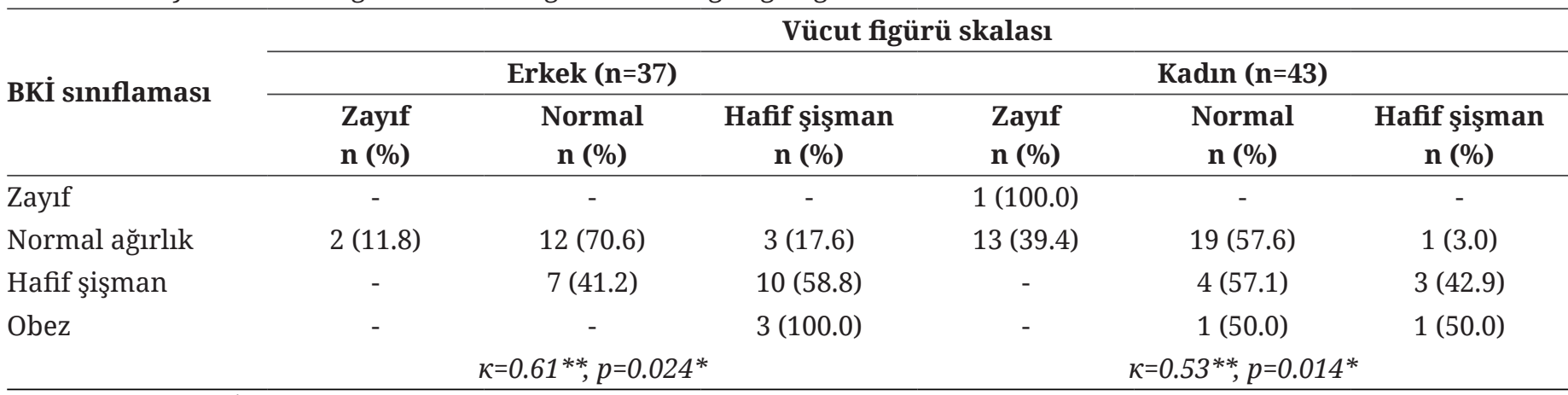

${ }^{*} p<0.05,{ }^{* *} \kappa: K a p p a$, BKİ: Beden kütle indeksi

Bireylerin vücut yağ yüzdesine (\%) göre beden ağırlığı algısı Tablo 4’te gösterilmiştir. Vücut yağ yüzdesine göre normal ağırlıktaki erkeklerin \%70.0’i kendini normal değerlendirirken, normal ağırlıktaki kadınlarda bu sıklık \%55.2'dir. Normal ağırlıktaki erkeklerin \%10.0’u, kadınların ise \%41.4'ü kendini zayıf olarak değerlendirmiştir. Obez erkeklerin \%33.3’ü, kadınların \%80.0’i normal ağırlıkta olduğunu düşünmektedir. Her iki cinsiyette de vücut yağ yüzdesi ile beden ağırlığı algı sınıflaması arasında tutarlılık olmadığı saptanmıştır ( $\mathrm{E} \kappa=0.84, \mathrm{p}=0.057, \mathrm{~K}$ $\kappa=0.16, p=0.655)$.

Çalışmaya katılan erkeklerin vücut farkındalık skoru ortalaması $80.5 \pm 14.2$, kadınların $83.0 \pm 12.7$ olarak bulunmuş, cinsiyete göre istatistiksel olarak anlamlı bir fark saptanmamıştır ( $p>0.05)$. Bireylerin vücut figürü skala değerlendirmelerinin vücut farkındalık skoru ile ilişkisi Tablo 5’te verilmiştir. Vücut figürünü doğru değerlendiren erkeklerin vücut farkındalık skoru, yanlış değerlendirenlerden anlamlı olarak 
daha yüksektir $(p=0.017)$. Kadınların vücut figürü skorları arasında anlamlı bir fark saptanmamıştır skala değerlendirmelerine göre vücut farkındalık $(\mathrm{p}>0.05)$.

Tablo 4. Bireylerin vücut yağ yüzdesine göre beden ağırlığı algısı

\begin{tabular}{|c|c|c|c|c|c|c|}
\hline \multirow{3}{*}{ Vücut yağ yüzdesi (\%) } & \multicolumn{6}{|c|}{ Vücut figürü skalası } \\
\hline & \multicolumn{3}{|c|}{ Erkek $(n=37)$} & \multicolumn{3}{|c|}{ Kadın $(n=43)$} \\
\hline & $\begin{array}{l}\text { Zayıf } \\
\text { n (\%) }\end{array}$ & $\begin{array}{c}\text { Normal } \\
\text { n (\%) }\end{array}$ & $\begin{array}{c}\text { Hafif şişman } \\
\text { n (\%) }\end{array}$ & $\begin{array}{l}\text { Zaynf } \\
\text { n (\%) }\end{array}$ & $\begin{array}{c}\text { Normal } \\
\text { n (\%) }\end{array}$ & $\begin{array}{c}\text { Hafif şişman } \\
\text { n (\%) }\end{array}$ \\
\hline Zaylf $(\mathrm{E} \leq 8, \mathrm{~K} \leq 21)$ & - & - & - & $2(33.3)$ & $3(50.0)$ & $1(16.7)$ \\
\hline Normal $(E=8.1-19.9, K=21.1-32.9)$ & $2(10.0)$ & $14(70.0)$ & $4(20.0)$ & $12(41.4)$ & $16(55.2)$ & $1(3.4)$ \\
\hline Hafif şişman $(E=20-24.9, K=33-38.9)$ & - & $3(27.3)$ & $8(72.7)$ & - & $1(33.3)$ & $2(66.7)$ \\
\hline \multirow[t]{2}{*}{ Obez $(\mathrm{E}: \geq 25, \mathrm{~K}: \geq 39)$} & - & $2(33.3)$ & $4(66.7)$ & - & $4(80.0)$ & $1(20.0)$ \\
\hline & \multicolumn{3}{|c|}{$\kappa=0.84^{*}, p=0.057$} & \multicolumn{3}{|c|}{$\kappa=0.16^{*}, p=0.655$} \\
\hline
\end{tabular}

${ }^{*} \kappa:$ Kappa

Tablo 5. Bireylerin vücut yağ yüzdesine göre beden ağırlığı algısı

\begin{tabular}{lcccc}
\hline & \multicolumn{4}{c}{ Vücut figürü skala değerlendirmesi } \\
\cline { 2 - 5 } Vücut yağ yüzdesi (\%) & \multicolumn{2}{c}{ Erkek (n=37) } & \multicolumn{2}{c}{ Kadın (n=43) } \\
\cline { 2 - 5 } & $\begin{array}{c}\text { Doğru } \\
(\mathbf{n}=\mathbf{2 2})\end{array}$ & $\begin{array}{c}\text { Yanlış } \\
(\mathbf{n}=\mathbf{1 5 )}\end{array}$ & $\begin{array}{c}\text { Doğru } \\
(\mathbf{n}=\mathbf{2 3})\end{array}$ & $\begin{array}{c}\text { Yanlış } \\
(\mathbf{n}=\mathbf{2 0})\end{array}$ \\
\hline & $\mathbf{( \mathbf { X }} \pm \mathbf{S})$ & $\left(\overline{\mathbf{X}}_{ \pm} \mathbf{S}\right)$ & $\mathbf{( \mathbf { X }} \pm \mathbf{S})$ & $\left(\overline{\mathbf{X}}_{ \pm} \mathbf{S}\right)$ \\
\hline Vücut farkındalık skoru & $83.8 \pm 13.06$ & $75.5 \pm 15.80$ & $80.7 \pm 13.16$ & $85.7 \pm 11.78$ \\
& & $z=1.610, p=0.017^{*}$ & $z=-1.158, p=0.247$ \\
\hline
\end{tabular}

${ }^{*} p<0.05$

Bireylerin medeni durum, sigara kullanımı ve alkol tüketim durumlarına göre vücut farkındalık skorları arasında anlamlı fark saptanmamıştır ( $>0.05)$. Hem cinsiyete göre hem de toplamda yapılan değerlendirmelerde vücut farkındalık skoru ortalamaları ile yaş, antropometrik ölçümler ve vücut bileşimleri arasında da anlamlı bir ilişki belirlenmemiştir $(p>0.05)$ (Veriler tabloda gösterilmemiştir).

\section{TARTIŞMA}

Vücut farkındalığı bireyi fiziksel, emosyonel, psikolojik ve sosyal yönden ele alan çok yönlü bir kavram olduğundan son yllarda özellikle fiziksel performans ve sağlıklı halin sürdürülmesi üzerine yapılan çalışmalarda kullanımı giderek artış göstermiştir $(2,22,23)$. Ancak literatürde vücut farkındalığının beslenme durumu ile ilişkisini değerlendiren çalışmalar son derece sınırlıdır.
Araştırmaya katılan erkeklerin yaş ortalaması $27.3 \pm 1.81$ yll, kadınların 27.0 \pm 2.05 yll olarak belirlenmiştir. Erkeklerin ortalama BKİ değeri $25.5 \pm 3.19 \mathrm{~kg} / \mathrm{m}^{2}$, kadınların ise $23.0 \pm 3.48 \mathrm{~kg} / \mathrm{m}^{2}$ dir. Obezite için bir tarama aracı olan BKİ sınıflamasına göre beden ağırlığı algısı her iki cinsiyette de tutarlı iken, vücut yağ yüzdesine göre yapılan vücut ağırlığı sınıflaması ile beden ağırlığı algısının tutarlı olmadığı saptanmıştır. Bu sonucun BKI sinıflamasına göre bireylerin büyük bir kısmı normal ve hafif şişman iken obezitenin tanımında da yer alan vücut yağ miktarı fazlalığına göre çoğunluğunun hafif şişman ve obez olmasından kaynaklandığı, bireylerin vücut ağırlığı değerlendirilirken BKİ ile birlikte vücut yağ oranının da göz önünde bulundurulması gerektiğini bir kez daha göstermektedir (24-26).

Vücut yağ oranının belirlenmesine ek olarak farklı antropometrik ölçümlerin kullanılması, ilişkili olan sağlık sorunlarının öngörülmesi ve risk etmenlerinin 
belirlenmesinde yardımcı yöntemler olarak karşımıza çıkmaktadır (27). Özellikle abdominal obezite ile önemli düzeyde ilişkili olan bel çevresi ölçümünde cinsiyete göre fark görülmezken erkeklerde boyun çevresi kalınlığına bağlı risk belirgin olarak daha yüksek bulunmuştur.

Yapılan araştırmalar cinsiyet farkı gözetmeksizin bireylerin vücut ağırlıklarını oldukları ağırlıktan daha düşük tahmin ettiğini ve bu durumun yeme bozukluğu tanısı olanlarda, adölesanlarda, fazla kilolu ve obez bireylerde daha belirgin olduğunu bildirmektedir (28-30). Kadınların vücut ağırlıklarını gerçek vücut ağırlıklarından daha düşük ya da daha yüksek algıladığını gösteren pek çok çalışma bulunmakta, bu durumun kadınların duygu durum değişiklikleri, çevresel etmenler ve sosyal çevreden daha fazla etkilenmesi ile ilişkili olabileceği düşünülmektedir (31-33).

Mevcut araştırmada BKİ ile vücut ağırlığı algı sınıflaması arasındaki tutarlılığın erkeklerde iyi, kadınlarda orta düzeyde olduğu saptanmıştır (sirasiyla $\kappa=0.61, p=0.024, \kappa=0.53, p=0.014$ ). Ülkemizde yapılan “Beden Ağırlığı Algısı Araştırması” sonuçlarına göre BKİ ile vücut ağırlığı algısı sınıflamasındaki tutarlılığın her iki cinsiyette de zayıf olduğu, iki kişiden birinin vücut ağırlığını doğru algılayamadığı, ancak öğrenim düzeyi arttıkça doğru beden algısına sahip olanların sayısının arttığı bildirilmiştir (34). Bu çalışmada bireylerin tamamının üniversite mezunu olup sağlık alanında eğitim almaları ve bu alanda çalışmaya devam etmelerinin vücut ağırlığının doğru değerlendirilmesine katkı sağlayan en önemli etmen olduğu düşünülmektedir.

Vücut farkındalık anketinin Türkiye’ye uyarlamasının yapıldığı araştırmada ise katılımcıların vücut farkındalığı skorlarının ortalama 93.0 \pm 12.63 olduğu saptanırken, cinsiyete göre farklılık incelenmemiştir (20). Benzer şekilde erkeklerin vücut farkındalık skoru 95.08 \pm 14.59 , kadınların 94.36 \pm 13.88 olarak belirlendiği çalışmada, vücut farkındalık skorunun cinsiyetle ilişkisi değerlendirilmemiştir (2). Cinsiyete göre vücut farkındalık skorunun değerlendirildiği çalışmada ise anlamlı farklılık olmadığı belirlenmiştir (35). Bu çalışmada erkeklerin vücut farkındalık skoru $80.5 \pm 14.2$, kadınların 83.0 \pm 12.7 olarak hesaplanmış, çalışmalarla benzer şekilde cinsiyete göre anlamlı bir fark belirlenmemiştir $(\mathrm{p}<0.05)$. Bunun yanında vücut figürünü doğru değerlendiren erkeklerin vücut farkındalık skorları yanlış değerlendirenlere kıyasla anlamlı oranda yüksek bulunurken $(\mathrm{p}<0.05)$, kadınların vücut figürü değerlendirmeleri ile vücut farkındalık skorları arasında anlamlı fark saptanmamıştır ( $p>0.05)$. Erkeklerin görünüşleriyle ilgili daha gerçekçi olmalarının ve kaygılarının daha az olmasının beden algilarının ve farkındalıklarının daha yüksek ve tutarlı olması sonucunu doğurduğu düşünülmektedir.

Araştırmada cinsiyet ve antropometrik ölçümlerin yanında, bireylerin medeni durumları, sigara ve alkol kullanım durumları ile vücut farkındalık skorları arasındaki ilişki de incelenmiş, ancak çalışma grubu incelenen değişkenler açısından homojen özellik gösterdiğinden anlamlı ilişki saptanmamıştır ( $p>0.05)$.

Sonuç olarak, araştırmaya katılan bireylerin yarısından fazlasının vücut ağırlığını doğru tahmin ettiği, vücut figürü değerlendirmesini doğru yapan erkeklerin vücut farkındalık skorlarının daha yüksek olduğu görülmüştür. Cinsiyete göre vücut farkındalığı skoru ile bireylerin yaş, genel özellikler ve antropometrik ölçümleri arasında anlamlı ilişki saptanmamıştır. Araştırma sonuçlarının genele yayılabilmesi ve kanıt değerinin arttırabilmesi için daha fazla örneklem sayısına sahip, bireylerin sosyal ve mesleki yaşantısı, çalışma koşulları, aktivite düzeyi ve emosyonel durumu gibi birçok etmenin bir arada değerlendirildiği çalışmalara gerek duyulmaktadır. $\mathrm{Bu}$ bağlamda bu çalışmanın literatüre olan katkısı açısından son derece önemli olduğu düşünülmektedir.

Çıkar çatışması - Conflict of interest: Yazarlar çıkar çatışması olmadığını beyan ederler. - The authors declare that they have no conflict of interest. 


\section{KAYNAKLAR}

1. Price CJ, Thompson EA. Measuring dimensions of body connection: Body awareness and bodily dissociation. The JACM 2007;13(9):945-53.

2. Erden A, Altuğ F, Cavlak U. Sağlıklı kişilerde vücut farkındalık durumu ile ağrı, emosyonel durum ve yaşam kalitesi arasındaki ilişkinin incelenmesi. Journal of Kartal Training \& Research Hospital/Kartal Egitim ve Arastirma Hastanesi Tıp Dergisi 2013;24(3):145-50.

3. Neumark Sztainer D, Eisenberg EM, Wall M, Loth AK. Yoga and pilates: Associations with body image and disordered eating behaviors in a population based sample of young adults. IJED 2011;44(3):276-80.

4. Mehling WE, Wrubel J, Daubenmier JJ, Price CJ, Kerr CE, Silow T, et al. Body awareness: construct and self-report measures. PloS one 2009;4(5):e5614.

5. Ginzburg K, Tsur N, Barak-Nahum A, Defrin R. Body awareness: Differentiating between sensitivity to and monitoring of bodily signals. Int J Behav Med 2014;37(3):564-75.

6. Dittmann KA and Freedman M. Body awareness, eating attitudes, and spiritual beliefs of women practicing yoga. Eating Disorders 2009;17(4):273-92.

7. Catalan-Matamoros D, Helvik-Skjaerven L, LabajosManzanares MT, Martínez-de-Salazar-Arboleas A, Sánchez-Guerrero E. A pilot study on the effect of Basic Body Awareness Therapy in patients with eating disorders: a randomized controlled trial. Clin Rehabil 2011;25(7):617-26.

8. Pallan MJ, Hiam LC, Duda JL, Adab P. Body image, body dissatisfaction and weight status in South Asian children: a cross-sectional study. BMC Public Health 2011;11(1):21.

9. El-Sherbiny NA, Mashahit MA, Sheir RE. Assessment of public awareness about body measurements among Fayoum population. Health 2014;6(3):212-7.

10. Koithan M. Mind-body solutions for obesity. J Nurse Pract 2009;5(7):536-7.

11. James PT, Leach R, Kalamara E, Shayeghi M. The worldwide obesity epidemic. Obesity 2001;9(S4):228-33.

12. Morotti E, Battaglia B, Paradisi R, Persico N, Zampieri M, Venturoli S, et al. Body mass index, Stunkard Figure Rating Scale, and sexuality in young Italian women: a pilot study. J Sex Med 2013;10(4):1034-43.

13. Lohman T, Roche A. Martorell R. Anthropometric standardization reference manual. Champaign, Illinois: Champaign, IL: Human Kinetics Books Publisher; 1988.

14. World Health Organization. Diet, nutrition and the prevention of chronic diseases: Report of a Joint WHO/
FAO expert consultation Vol.916. Geneva, 2003.

15. World Health Organization (WHO). Waist circumference and waist-hip ratio: Report of a WHO expert consultation. Geneva, 2011.

16. Ben Noun LL, Sohar E, Laor A, Neck circumference as a simple screening measure for identifying overweight and obese patients. Obesity 2001;9(8):470-7.

17. Gallagher D, Heymsfield BS, Heo M, Jebb AS, Murgatroyd RP, Sakamoto Y. Healthy percentage body fat ranges: an approach for developing guidelines based on body mass index. Am J Clin Nutr 2000;72(3):694-701.

18. Lynch E, Liu K, Wei SG, Spring B, Kiefe C, Greenland P. The relation between body size perception and change in body mass index over 13 years: the Coronary Artery Risk Development in Young Adults (CARDIA) study. Am J Epidemiol 2009;169(7):857-66.

19. Shields SA, Mallory ME, Simon A. The body awareness questionnaire: reliability and validity. J Pers Assess 1989;53(4):802-15.

20. Karaca S. Vücut farkındalığı anketinin Türkçe uyarlaması: geçerlik ve güvenirlik çalışması [Bilim Uzmanlığı Tezi]. Muğla Sıtkı Koçman Üniversitesi, Muğla; 2017.

21. Landis JR, Koch GG. The measurement of observer agreement for categorical data. Biometrics 1977;33(1):159-74.

22. Mehling WE, Gopisetty V, Daubenmier J, Price JC, Hecht FM, Stewart A. Body Awareness: a phenomenological inquiry into the common ground of mind-body therapies. Philos Ethics Hum Me 2011;6(1):6.

23. Fuchs T, Koch SC. Embodied affectivity: on moving and being moved. Front Psychol 2014;5:508.

24. Ejike CE, Ijeh II. Obesity in young-adult Nigerians: variations in prevalence determined by anthropometry and bioelectrical impedance analysis, and the development of body fat prediction equations. Int Arch Med 2012;5(1):22.

25. Ranasinghe C, Gamage P, Katulanda P, Andraweera N, Thilakarathne S, Tharanga P. Relationship between Body mass index (BMI) and body fat percentage, estimated by bioelectrical impedance, in a group of Sri Lankan adults: a cross sectional study. BMC Public Health 2013;13(1):797.

26. Doğan B, Öner C. Obez bireylerde iki farklı yöntemle hesaplanan vücut yağ oranının antropometrik değerler ve lipid parametreleri ile ilişkisi. FNG \& Bilim Tıp Dergisi 2015;1(3):124-8.

27. Alberti KG, Zimmet P, Shaw J. The metabolic 
syndrome-a new worldwide definition. The Lancet 2005;366(9491):1059-62.

28. Cox TL, Zunker C, Wingo B, Thomas DM, Ard JD. Body image and quality of life in a group of African American women. Soc Indic Res 2010;99(3):531-40.

29. Smalley KB, Warren JC, Morrissey MBD. Discrepancy between actual and perceived weight status in rural patients: Variations by race and gender. J Health Care Poor Underserved 2017;28(1):514.

30. Dion J, Blackburn ME, Auclair J, Laberge L, Veillette S, Gaudreault M, et al. Development and aetiology of body dissatisfaction in adolescent boys and girls. Int J Adolesc Youth 2015;20(2):151-66.

31. Acevedo P, López-Ejeda N, Alférez-García I, MartínezÁlvarez JR, Villarino A, Cabañas MD, et al. Body mass index through self-reported data and body image perception in Spanish adults attending dietary consultation. Nutrition 2014;30(6):679-84.

32. Kagawa M, Kuroiwa C, Uenishi K, Mori M, Dhaliwal S, Hills $\mathrm{P}$, et al. A comparison of body perceptions in relation to measured body composition in young Japanese males and females. Body Image 2007;4(4):372-80.

33. Alwan H, Viswanathan B, Williams J, Paccaud F, Bovet P. Association between weight perception and socioeconomic status among adults in the Seychelles. BMC Public Health 2010;10(1):467.

34. T.C. Sağlık Bakanlığı, Sağlığın Geliştirilmesi Genel Müdürlüğü. Türkiye Beden Ağırlığı Algısı Araştırması. Ankara, 2012. Erişim: https://sbu.saglik.gov.tr/ Ekutuphane/Yayin/449. Erişim tarihi: 10.04.2018.

35. Akdeniz B. Yoga yapan bireylerin cinsel doyumlarının, beden farkındalıklarının ve yaşam memnuniyetlerinin değerlendirilmesi [Bilim Uzmanlığı Tezi]. Işık Üniversitesi, İstanbul; 2017. 